\title{
LAESIO ENORMIS, CODUL CIVIL AUSTRIAC ŞI O AFACERE DE FAMILIE
}

DOI: 10.24193/SUBBiur.64(2019).4.2 Published Online: $2019-12-31$

\section{Mircea Dan Bob*}

Rezumat: $O$ căutare prin arhiva familiei mi-a revelat o serie de contracte de vânzare perfectate de străbunicii mei acum aproape un secol. Clauzele acestora se referă în mod constant la art. 934 Cod civil austriac, privind leziunea enormă. Analiza de față își propune să urmărească aplicarea textului în Transilvania, pornind de la rădăcinile romanistice: cum a pătruns soluția romană în dreptul austriac? Care a fost aplicabilitatea practică a acesteia? Sensul ei roman a fost fidel păstrat? Scopul final va fi acela de a prezenta o evoluție de ordinul istoriei dreptului asupra leziunii, pentru a veni în ajutorul dezbaterilor actuale privindu-i statutul în codul civil român actual.

Cuvinte cheie: leziune, laesio enormis, drept roman, contracte, vânzare, preț, viciu de consimțământ.

* Profesor, Facultatea de Drept a Universității Babeș-Bolyai din Cluj; mirceabob@law.ubbcluj.ro. 


\title{
LAESIO ENORMIS, THE AUSTRIAN CIVIL CODE AND A FAMILY BUSSINESS
}

\begin{abstract}
While searching through family papers, I discovered some sale contracts concluded a hundred years ago by one of my ancestors. Their clauses were constantly referring to the $\$ 934$ ABGB's provisions on laesio enormis. It is the object of my paper to give an account on the application of this text in Romanian historical province of Transylvania, by comparing it to its Roman origins: how was the Roman law solution received in the ABGB? What was the extent of its application into practice? Did it succeed to stay true to its original sense? The ultimate purpose of the whole analysis will be to give a brief legal history account on the lesion, to help nowadays debates on its status in the recently revised Romanian civil code.
\end{abstract}

Keywords: lesion, laesio enormis, Roman law, contracts, sale, price, vice of consent.

Căutând prin arhiva familiei, am dat peste o serie de contracte de vânzare-cumpărare, încheiate în perioada interbelică de străbunicii mei. Achiziționaseră imobile sub imperiul codului civil austriac - în vigoare în părțile ardelene ale țării până la extinderea din 1947 a legislației civile a Vechiului Regat. Una din clauzele pe care am observat-o a reveni în fiecare contract era aceea de la nr. 6: renunțarea la beneficiul art. 934 ABGB, privind leziunea enormă. 


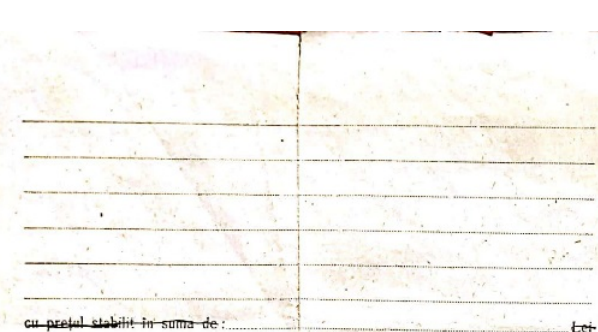

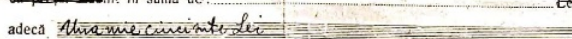

1. Vânzătorul lasă să treacă accastă parte dé moşie descrisă mai sus, in proprictatea asiguratā a cumpărător țứ

2. Numitul cumpărător primęe imobilul descris mai sus in preful arătat

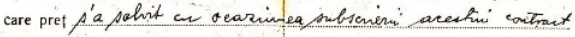

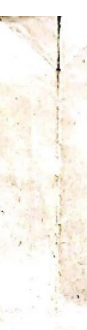

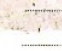

Acest contract a fost cetit şi exphicat parrţilor, care inf̧elegand toate punctele numite, explicarea fiind făcută pe limbă lor maternă, ca autentificare și au semnat acest contract cu mâna lor sau semnul br propriu.

acest contract cu mâna lor sau
Data fa $3 / x-926$

S'a explicat și semnat inaintea noastrơ:

Sprictanci.

Yoaw Gop: ․․
Hertion doise spow Mistierz

3. Cumpårătorosil trec_._cu inceperea zilei de azi in posesia moșiei și de azi inainte se bucură de tot profitul ei, purtând totdeauna și toate sarcinile şi birurile (dările) ei.

4. Vânzători" indreptă leșe, pe cumpărător(i) a intabula în cartea funduară imobilul numit, fără a-l mai întreha.

5. Taxele de, transcriere și cheltuelile de intabulare le supoartå Cumpranaton

6. Parţile renunfa reciproc la dreptul lor bazat pe $\$ 954$ din codul civil

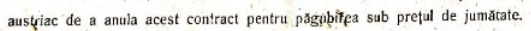

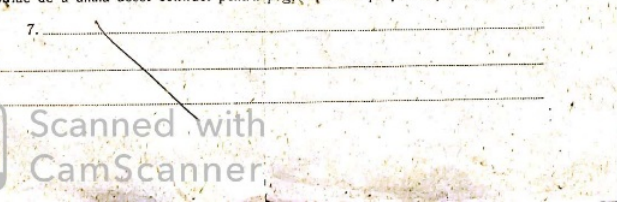


.

4.Vanzătorii indreptaţesc pe cumpărătorii să intabuleză dreptul de proprietate asupra imobilului sus anintit far de a mai fi intrebaţi §i scutiţi de uzufruct.-

5. I'axele de transcriere şi cheltuielile de intabulate le supoartæ cumparatori.

6.Parţile renunţa reciproc la dreptul lor intemeiat pe $\S 934$ din codul civil austriac pentru cauza de leziune peste jumatate din preţul ordinar.

Acest contract a fost cetit sii esplicat partilor, care inţelegând toate punctele numite,explicarea fiind făcutæ in limba lor maternă ca autentificare au semnat acest contract cu mâna. lor propriu. .

Cluj la 15 . Iulie 1934

S'a explicat şi semnat inaintea noastræ:

Martori. churesan 浐e

Joan crisan

Parvan Yearz

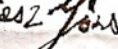

svanle sauch

Irins OPelace

Fontlutaren

himithefan

Thantes 2 Yis

m. Doritidsume

No $15436 / 1934$ of.

Sis intabulat plreptuse sle pinpasictate fub

O1-2, in of Cot 440 a copmena Pardu

Bhy.10 Tomuani 1935

dy.

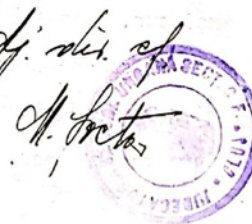


Am redat mai sus partea finală a două dintre contractele pe care le-am identificat. Romanistul din mine a sesizat imediat legătura cu noțiunea apărută în dreptul postclasic și transmisă nouă prin dispozițiile din Codex. Civilistul din mine şi-a formulat imediat două ipoteze:

a) ținând cont de repetarea standardizată a respectivei clauze în fiecare contract, oare nu cumva aceasta devenise una standardizată?

b) din eventualul răspuns afirmativ, ar decurge cea de-a doua ipoteză: cum și cât din regula romană se transmisese în Codul civil austriac?

Răspunsurile pe care voi încerca să le identific au și un scop mediat, pentru că vor fi urmate de studierea unui terț și ultim aspect: mai există leziunea enormă în dreptul civil român și comparat? Textele actualului Cod civil român au generat în literatura de specialitate critici legate de fundamentarea leziunii, plasată de legiuitorul nostru în categoria viciilor de consimțământ ${ }^{1}$. Analiza pe care o propun nu va da un răspuns direct îndoielilor civiliste exprimate. Aceasta are doar scopul de a pune la dispoziția civilistului de azi experiența istoriei dreptului, în sensul de a răspunde la întrebarea următoare: se pretează leziunea la o fundamentare unică și coerentă logic?

1. Noțiunea de preț echitabil (iustum pretium) nu era cunoscută în dreptul clasic roman ${ }^{2}$.

Este probabil si motivul pentru care citim la jurisconsulții clasici:

1 D. CHIRICĂ, Leziunea între reglementarea vechiului şi noului Cod civil, în SUBB Iurisprudentia nr. 4/2013, pp. 25-44, disponibil la http://arhivastudia.law.ubbcluj.ro/articol/574.

${ }^{2} \mathrm{O}$ excepție era una ce ținea de persoane, mai degrabă decât de contracte: incapacitatea fiilor de familie mai tineri de douăzeci și cinci de ani. Aceștia puteau cere restituirea prețului plătit pentru o vânzare. 
„Este normal ca fiecare să încerce, pe diverse căi, să tragă cel mai mare folos."

„Este normal la o vânzare să cumperi la cel mai mic preț lucrul cel mai valoros şi să vinzi pentru mai mult ceea ce este de mai mică valoare, în funcție de jocul târguielilor."4

Lucrurile se nuanțează însă în dreptul postclasic, astfel că ajungem să citim în Codexul lui Iustinian următoarele texte:

Imperatores Diocletianus, Maximianus. Rem maioris pretii si tu vel pater tuus minoris pretii, distraxit, humanum est, ut vel pretium te restituente emptoribus fundum venditum recipias auctoritate intercedente iudicis, vel, si emptor elegerit, quod deest iusto pretio recipies. Minus autem pretium esse videtur, si nec dimidia pars veri pretii soluta sit. [a.285] (C. 4.44.2)

Imperatores Diocletianus, Maximianus. Si voluntate tua fundum tuum filius tuus venumdedit, dolus ex calliditate atque insidiis emptoris argui debet vel metus mortis vel cruciatus corporis imminens detegi, ne habeatur rata venditio. Hoc enim solum, quod paulo minori pretio fundum venumdatum significas, ad rescindendam emptionem invalidum est. Quod videlicet si contractus emptionis atque venditionis cogitasses substantiam et quod emptor viliori comparandi, venditor cariori distrahendi votum gerentes ad hunc contractum accedant vixque post multas contentiones, paulatim venditore de eo quod petierat detrahente, emptore autem huic quod obtulerat addente, ad certum consentiant pretium, profecto perspiceres neque bonam fidem, quae emptionis atque $v$ enditionis conventionem tuetur, pati neque ullam rationem concedere rescindi propter hoc consensu finitum contractum vel statim vel post pretii quantitatis disceptationem: nisi minus dimidia iusti pretii, quod

3 Pomponius, Dig. 4.4.16.4: in pretio emptionis ... naturaliter licere contrahentibus se circumvenire.

4 Paulus, Dig. 19.2.22.3: Quemadmodum in emendo et vendendo naturaliter concessum est quod pluris sit minoris emere, quod minoris sit pluris vendere et ita invicem se circumscribere. 
fuerat tempore venditionis, datum est, electione iam emptori praestita servanda. [a. 293] (C. 4.44.8)

Textele sunt prezentate în Codex a fi provenind din perioada domniei lui Dioclețian. Datarea este însă controversată. Unii romanişti identifică indicii în însuşi conţinutul acestora, pentru a concluziona că ar fi fost interpolate de comisia lui Iustinian - care a redactat ediția din anul 534 a codului. În plus, analizând soluția pe fond, cercetătorii în cauză susțin că localizarea temporală de mai sus devine discutabilă.

Conform textelor de mai sus, cel care a vândut un teren agricol pentru un preț inferior jumătății valorii sale juste, va putea invoca faptul că a suferit o leziune enormă. Admiterea pretenției sale poate avea ca rezultat fie desființarea retroactivă a vânzării fie complinirea prețului.

În susținerea originii dioclețiene a textelor, se arată că Dioclețian a dat edictul de pretiiis rerum venalium, din care se crede azi că ar face parte și laesio enormis. Dar - s-a replicat - edictul în cauză era o măsura de drept public (nu privat), menită să protejeze de inflație cumpărătorii (nu vânzătorii) făcând parte din unele categorii defavorizate, prin instituirea unor tarife minimale pentru bunuri și servicii.

Pe de altă parte, Dioclețian a rămas în istorie drept un împărat conservator, un promotor al soluțiilor dreptului clasic roman. Or, soluția în discuție contrazice flagrant autonomia decizională a părților dintr-o relație contractuală, condensată în expresia ius vigilantibus scriptum: dreptul privat roman clasic nu-și propusese să edicteze reguli menite a ocroti părțile, ci a fost un set de reguli-cadru minimale pentru voința atotputernică a contractanților. Odată această voință angajată, partea este ținută fără doar şi poate la executarea întocmai a prestațiilor asumate. 
Ținând seama că nici Codul Theodosian (a. 439) nu menționează deloc laesio enormis, contestatarii paternității dioclețiene a soluției consideră că aceasta ar aparține absolutismului statului-providență instaurat de Iustinian. Umanismul promovat de filosofia morală stoică și de creștinism ar fi considerat că se poate trece peste claritatea şi scopul educativ al regulilor stricte şi severe, preferându-se în cazuri excepționale soluții echitabile; se poate da astfel dovadă de înțelegere și se poate evita producerea unor consecințe prea dure. Replica dată acestor considerații este că argumentul interpolării nu ar fi decisiv și că absența referirii în Codex Theodosianus la cele două rescripte ale lui Dioclețian poate însemna doar că nu ar fi primit consacrare legislativă generică decât sub Iustinian (dar au fost aplicate practic, pe fondul inflației galopante) 5 .

În ce mă privește, mi se pare mai probabil ca textul să aparțină redactorilor Codexului. Aceasta se susține și contextual: dacă inflația aducea consecințe practice injuste evidente, cum este posibil ca rescriptele lui Dioclețian să fi fost ,uitate” de către comisia lui Teodosiu al II-lea? Pe de altă parte, apariția lor abia sub Iustinian se justifică ținând cont de consecințele inechitabile ale fiscalității severe instaurate de acesta: țăranii fermieri nu mai puteau rezista şi ajungeau să-şi vândă pământurile la prețuri derizorii. Cumpărătorii erau deținătorii de capital din mediul urban, interesați să investească în valori stabile, cum sunt terenurile agricole. Este vorba de aşanumiții potentes: senatori, înalți funcționari, particulari bogați și bisericile creștine.

5 Există și opinia lui B. SIRKs, care vede în crearea iustiniană a leziunii enorme o specializare a posibilității existente deja în dreptul clasic, în caz de restitutio in integrum consecutivă unei vânzări, când cumpărătorul putea păstra bunul plătind vânzătorului un complement de preț. 
2. Soluția din C. 4.44 .2 a fost una de aplicare excepțională, la cazul individual al unui anume Aurelius Lupus ${ }^{6}$.

Vânzătorul a primit posibilitatea de a cere desființarea (resciziunea) vânzării pe care o consimțise la un preț mai mic decât jumătatea valorii reale a pământului său. Cumpărătorului i s-a acordat posibilitatea concomitentă de a salva contractul, achitând restul de preț. O rezolvarea echitabilă, dar - pe fond - o simplă rezolvare de speță, nicidecum o regulă generalizabilă. Extinderea la alte ipoteze a survenit abia în jurisprudența medievală. Glosatorii şi postglosatorii (comentatorii Corpusului iustinianeu, sec. XIIXIV) au aplicat-o și la alte categorii decât țăranii, la alte bunuri decât terenurile agricole și chiar pentru alte contracte decât vânzarea!

Analogia a fost posibilă, deoarece comentatorii întemeiau resciziunea pe ideea de dol. Așa a ajuns să fie catalogată în dreptul civil francez modern între viciile de consimțământ. Or, juriștii romani (și, pe urmele lor, canoniștii medievali) avuseseră o viziune obiectivă, pur economică a leziunii, considerând că orice bun are o valoare în sine, independentă de ce vor părțile să facă cu acesta; în atare concepție, leziunea era un simplu corectiv, exterior cadrului contractual.

Dar analogia prezentată a fost acceptată în grade diferențiate de diverșii juriști ai perioadei, în funcție de cât de departe au mers în interpretarea izvoarelor romane și de măsura în care au cedat ideii de echivalență a prestațiilor în contracte.

${ }^{6}$ Și nu de aplicare generală, cum se susține că ar fi primit prin constituţiile iustiniene din Codex rescriptele anterioare ale lui Dioclețian. 
3. Laesio enormis a ajuns în timp să aibă un destin comparabil cu cel al cauzei actului juridic - o altă soluție romană de speță, ridicată la rang de regulă generală de juriștii europeni.

Nu s-a putut niciodată răspunde în mod unitar la întrebări precum:

- cum aplicăm principiul pentru cumpărătorul constrâns de circumstanțe să achiziționeze la mai mult de dublul valorii reale?

- de ce să luăm reperul arbitrar al jumătăţii valorice? de ce să nu se stabilească alte limite, aşa cum s-a procedat în landul Würtemberg (sec. XVI și XVII, o treime) şi în Franța (1804, Codul Napoléon, cu proporția de 5/12)?

- cumpărătorul trebuie să complinească prețul real integral sau numai diferența până la jumătatea acestuia?

Dincolo de aceste aspecte tehnice, criticile aduse laesio enormis au fost ocazionate de o problemă de fond: ce înseamnă prețul just/real?

În ochii liberalismului economic occidental (începând din sec. XVII), nu există un preț just sau unul real: prețul este cel pe care indivizii, care sunt părți într-un contract concret, îl stabilesc în funcție de circumstanțele particulare în care se găsesc. Pe această linie umanistă (şi utilitaristă), se înscria celebrul pasaj extras din Leviatanul lui Hobbes:

"The value of all things contracted for, is measured by the appetite of the contractors: and therefore the just value, is that which they be contended to give"?.

Laesio enormis a ajuns totuşi până în unele coduri civile moderne. Dar a reuşit numai pentru că scolasticii medievali şi apoi partizanii dreptului natural au ridicat echivalența prestațiilor în materie contractuală la nivel de principiu. Ei s-au pronunțat astfel pe filieră aristotelică. Stagiritul scrisese

7 Th. HobBes, Leviatanul I.15. 
Etica Nicomahică faptul că niciuna din părțile unui contract nu se poate îmbogăți pe seama celeilalte. Ideea a fost preluată de Sf. Toma de Aquino în sec. XIII, de la care a intrat în dreptul canonic prin influența Sf. Ambrozie, ajungându-se să fie considerată păcat orice abatere de la prețul just. Trebuie precizat că justețea prețului, ca aplicare a egalității enunțate, nu se raporta la vreo valoare intrinsecă şi permanentă a obiectului vânzării sau la costurile sale de producție. Juriștii medievali şi ius naturaliștii considerau că este just/real prețul stabilit de piață, pe baze concurențiale. Aşa s-a ajuns, de exemplu, ca în Vechiul drept cutumiar francez să se admită leziunea în materie de vânzare mobiliară: soluția s-a născut din necesitatea practică de a proteja micii producători de cupiditatea comercianților. Începând din sec. XIV, parlamentele încep însă să refuze să acorde resciziunea în materie mobiliară cumpărătorilor, apoi și vânzătorilor. Domeniul leziunii revine treptat la cazul singular de laesio enormis din Dreptul Roman.

4. Până şi credința în capacitatea cuiva de a atinge echivalența prestaților s-a diminuat în timp şi în plan teoretic.

Sub influența umanismului la modă în şcoala Dreptului natural a sec. XVII, noțiunea de autonomie de voință a început să câştige teren în fața noțiunii metafizice/ius naturaliste de justiție contractuală. Autonomia de voință s-a impus sub influența ideilor lui Kant şi Fichte, receptaţi de juriștii germani de început de sec. XIX (Eichorn, Savigny) și apoi și de cei elvețieni (Brocher) și francezi (Foelix, Weiss). Astfel de circumstanțe au dus la abandonarea totală a laesio enormis, începând cu sec. XIX. Singurele coduri moderne care au reținut-o au fost cel francez din $1804^{8}$ și cel austriac din 1811.

\footnotetext{
${ }^{8}$ PORTALIS, principalul tribun redactor al codului, scria: „La liberté de contracter ne peut être limitée que par la justice, par les bonnes mœurs, par l'utilité publique." (Discours, în FENET, Recueil ..., vol. I, p. 510).
} 
Tribunalele din Africa de Sud s-au opus reținerii sale în corpusul de reguli Romano-Olandeze; legiuitorul sud african a procedat apoi (1952) la abrogarea expresă pentru viitor a laesio enormis din practica instanțelor.

5. Codul civil austriac este cel care ne interesează în acest punct.

Art. 934 prevede că, în contractele sinalagmatice, partea care a primit mai puțin de jumătate din ceea ce ea a dat celeilalte părți după valoarea ordinară, are dreptul de a cere desființarea contratului şi repunerea în situația anterioară. Cocontractantul are însă dreptul de a salva convenţia, declarânduse gata să complinească prestația până la valoarea obişnuită, disproporţia fiind evaluată raportat la data contractării甲. Atacarea vânzării pentru leziune enormă se prescria extinctiv în termen de trei ani, conform art. 1487 ABGB.

Textul s-a văzut însă din start redus la tăcere în practică, unde renunțarea expresă la beneficiul său - permisă de art. 935 - a devenit clauză standard. Contractanții români din Transilvania nu au făcut aici decât să imite pe cei austrieci. Privind lucrurile din perspectiva istoriei comparate a dreptului, nu găsim ceva absolut nou. În Vechiul Drept cutumiar francez, încă din sec. XIII, notarii inserează fie declarații de renunțare la invocarea leziunii în actele de vânzare pe care le întocmesc, fie donația de către vânzător a diferenței valorice către cumpărător. Notarii francezi procedau astfel numai şi numai din prudență; receptarea ştiințifică încă din sec. XII a Dreptului Roman nu apucase încă să impregneze practica, pentru a se referi la laesio enormis.

6. Iată deci că ipoteza de la punctul a) se verifică:

Laesio enormis, o rezolvare în echitate inventată în dreptul roman postclasic, a ajuns pe bazele teoretice ale justiției

9 Cas. III, dec. 616/10.IV.1930, în Dreptatea 1931.64 nr. 42.

61 
contractuale egalitare până în codul modern austriac; dar aplicarea sa practică a ajuns să fie anulată printr-o clauză devenită standard - aşa cum sunt și cele din contractele străbunicilor autorului acestor rânduri.

Concluzia noastră se verifică și în extrem de săraca jurisprudență apărută în publicațiile de specialitate De exemplu, Curtea noastră de casație a respins pretenția vânzătorilor de a se aplica dispozițiile art. 934 ABGB referitoare la leziunea enormă, câtă vreme renunțaseră expres, la data contractării, la acest beneficiu (art. 935 ABGB) ${ }^{10}$. Un comentator al codului austriac $^{11}$ arăta în deceniul al treilea al secolului trecut că art. 934 ABGB este o normă dispozitivă, astfel că poate fi înlăturat de părți fără a altera prin aceasta substanța contractului: excluderea în cauză este un element natural al contractului (naturalia negotii), admis de altfel de art. 935 ABGB.

7. Să urmărim acum destinul ulterior al laesio enormis.

Codul civil austriac a fost aplicat în zona Clujului până la extinderea în 1947 a legislației civile a Vechiului Regat. Or, leziunea între majori nu fusese acceptată în nicio ipoteză de comisia lui Cuza în $1864^{12}$, iar Decretul nr. 31/1954, referitor la persoanele fizice și juridice, nu a deviat de la această direcție. Codul a suferit însă o revigorare legislativă în 1979, când s-a interzis expres renunțarea la beneficiul articolului său 934! Este aceasta o revigorare

\footnotetext{
${ }^{10}$ Cas., dec. 1011/1925, citată în Şt. LADAY, Codul civil austriac în vigoare în Ardeal și completat cu legile și regulamentele modificatoare, cuprinzând și jurisprudență, vol. I, Cluj 1924, pp. 176177, p. 177 .

11 L. ANCA, Compendiu de drept civil, cuprinzând codul civil austriac în vigoare în Transilvania, comparat cu dreptul civil al părților ungurene și dreptul civil al Vechiului Regat, precum și modificările făcute prin legile de modificare, Cluj f.a. (192?) p. 145, 160 și 169.

12 Fără a intra în detalii care aici nu-și au locul, menționăm faptul că, în literatura noastră, s-a demonstrat că art. 699 c.civ.1864 - în materie de opțiune succesorală - nu reglementa de fapt un caz de leziune.
} 
a regulii romane? Fără îndoială, dar pe alte baze teoretice decât cele iustiniene. Pentru a le elucida și a da răspuns ipotezei de la punctul b), o mică incursiune în codurile civile europene este necesară.

Art. 138 BGB declară nul, la alin. (1), orice act juridic care aduce atingere bunelor moravuri. La alineatul secund, declară nul cu precădere orice act juridic în care prestațiile sunt disproporționate datorită stării de necesitate în care se găsește o parte, a lipsei sale de experiență, a lipsei capacității sale de a judeca sau a stării de slăbiciune în care se află. Altfel spus, conform textului german, este contrar bunelor moravuri (şi nul, ca urmare) orice contract în care o parte profită de slăbiciunea economică a celuilalt sau ignoră în mod nepermis faptul că ultimul a contractat numai datorită situației precare (de judecată, de sănătate) în care se afla.

O dispoziției asemănătoare se găseşte în art. 21 alin. (1) din Codul elvețian al obligațiilor ${ }^{13}$. De asemenea, art. 388 C.civ. polonez reglementează aşa-numita „exploatare”, pentru ceea ce tradiția desemna prin leziune: prestațiile din orice contract bilateral având ca obiect bunuri pot fi redimensionate de instanță sau, după caz, se poate ajunge la desființarea retroactivă a contractului, când se constată o disproporție semnificativă între beneficiile părților, datorată stării de nevoie în care se găsea păgubitul (stare cunoscută de cel care a profitat). ${ }^{14}$

8. Care este situația în dreptul civil român postmodern?

Într-un raport la un congres internațional, un avocat român interbelic $^{15}$ întreprindea o analiză istorică a problemei, apoi sesiza faptul că

\footnotetext{
13 „En cas de disproportion évidente entre la prestation promise ....”

14 T. Szpila, Laesio enormis a instytucja wyzysku, publicat 23.IV.2014, (data ultimei accesări: 01.09.2019), disponibil la: https://europeanlegalculture.wordpress.com/2014/04/23/laesioenormis-a-instytucja-wyzysku/.

15 Gr. PhereKYDE, Le problème de la lésion, în Pandectele Române 1932.IV.203-208.
}

\section{3}


existaseră în jurisprudența română spețe care ar fi reclamat existența în Codul civil de la 1864 a leziunii între majori. Oferă exemplul de vânzare a imobilului de către o orfană a doua zi după majorat: convinsă că face un târg bun, în fapt și-a ruinat jumătate din avere.

Un pasaj din rândurile scrise de un alt avocat român al epocii ne relevă preocuparea pentru revigorarea laesio enormis:

„Trebuie să avem în legislațiunea noastră civilă o teorie a leziunii enorme, care să opereze atât în materie mobiliară cât și imobiliară, atât în beneficiul vânzătorului cât și al cumpărătorului sau mai general în beneficiul celor două părți dintr-un contract bilateral. Nu trebuie ca o limită aritmetică convențională să fie indicele de cetit automat, când este cazul unei vătămări pentru caz de leziune, ci trebuie ca numai aprecierea unor experți sau judecători s-o exprime, fără s-o lase aprecierii cu totul arbitrare a părților. Și să nu pară că explicațiunea se restrânge la vânzare, menționez că aşa se întâmplă la orice act bilateral." 16

Răspunsul pozitiv a fost dat de codul civil român din 2011:

Art. 1206 alin. (1): „,...] consimțământul este viciat în caz de leziune."

Art. 1221 alin. (1): „Există leziune atunci când una dintre părți, profitând de starea de nevoie, de lipsa de experiență ori de lipsa de cunoștințe a celeilalte părți, stipulează în favoarea sa ori a unei alte

16 M. S. TEOdoru, Laesio enormis, în Gazeta tribunalelor nr. 8-9/1937, p. 4. V. contra, E. B., Problema leziunii, în Pagini juridice (VI) 1938.6.112-117., unde autorul face niște confuzii de ordin istoric pentru a argumenta, în esență, că numai un viciu de consimțământ ar putea duce la anularea contractului bilateral disproporționat sub aspectul prestației. Or, în opinia autorului, criteriile obiective pe care laesio enormis se bazează nu pot fi acceptate pentru a desființa convenția părților. Această opinie era depăşită încă de când a fost emisă (1938), leziunea fiind deja intrată în categoria viciilor de consimțământ.

\section{4}


persoane o prestație de o valoare considerabil mai mare, la data încheierii contractului, decât valoarea propriei prestații.”

Art. 1222 alin. (1): „Partea al cărei consimțământ a fost viciat prin leziune poate cere, la alegerea sa, anularea contractului sau reducerea obligațiilor sale cu valoarea daunelor-interese la care ar fi îndreptățită.

(2) [...] acțiunea în anulare este admisibilă numai dacă leziunea depășește jumătate din valoarea pe care o avea, la momentul încheierii contractului, prestația promisă sau executată de partea lezată (s.n., MDB). Disproporția trebuie să subziste până la data cererii de anulare.

(3) În toate cazurile, instanța poate să mențină contractul dacă cealaltă parte oferă, în mod echitabil, o reducere a propriei creanțe sau, după caz, o majorare a propriei obligații (s.n., MDB) [...].”

9. Prin prisma datelor de drept civil comparat redate, sunt semne clare că individualismul absolut nu a avut viață lungă și că doctrina egalității schimburilor a revenit.

De observat însă că revenirea se bazează acum pe alte temeiuri: cele ale mult mai recent inventatului drept al consumației. Dacă examinăm variantele revizuite ale codurilor europene actuale, observăm fără dificultate cum arhitectura clasică (de origine romană, în general) a materiei obligațiilor este „infestată” de noțiunile dezvoltate in practica protecției consumatorului.

$\mathrm{Cu}$ alte cuvinte, laesio enormis revine, principial, în contextul necesităţilor de reglementare ale societății de consum. Este vorba de un set de reguli încă în curs de construire, pentru că îmi pare a se pune întrebarea: problema concretă se poate rezolva prin intruziunea în contract sau prin edificarea unui corpus nou și coerent de drept al consumației? O întrebare pentru al cărei răspuns, așa cum se vede din cele 
expuse până aici, experiența Dreptului Roman este mai mult decât o afacere de familie ...

\section{BIBLIOGRAFIE}

L. ANCA, Compendiu de drept civil, cuprinzând codul civil austriac în vigoare în Transilvania, comparat cu dreptul civil al părților ungurene și dreptul civil al Vechiului Regat, precum și modificările făcute prin legile de modificare, Cluj f.a. (192?) p. 145, 160 și 169;

E. B., Problema leziunii, în Pagini juridice (VI) 1938.6.112-117;

M. D. BoB, Manual de drept privat roman, Bucureşti 2019, p. 200 și 247;

D. CHIRICA, Leziunea între reglementarea vechiului și noului Cod civil, în SUBB-Iurisprudentia 4/2013, pp. 25-44, disponibil la: http://arhivastudia.law.ubbcluj.ro/articol/574;

D. Deroussin, Histoire du droit des obligations, Paris 2007, pp. 406-425

J-Ph. Dunand, B. Schmidlin, B. Winiger, Droit privé romain. II. Obligations, Geneva 2010, p. 85;

A. GUARINO, Diritto privato romano, Napoli 2001, pp. 887-888;

J-Ph. LEVY, A. CASTALDO, Histoire du droit civil, Paris 2002, pp. 215-216, 334, 722-723, 793-796, 820-823;

Şt. LADAY, Codul civil austriac în vigoare în Ardeal și completat cu legile și regulamentele modificatoare, cuprinzând și jurisprudență, vol. I, Cluj 1924, pp. 176-177;

L. DE LIGHT, în P. DU PLESSIS, C. ANDO, K. TUORI, The Oxford Handbook of Roman Law and Society, Oxford 2016, p. 667;

Gr. PHEREKYDE, Le problème de la lésion, în Pandectele Române 1932.IV.203-208; 
P. PORUȚIU, Problema prețurilor în procesele privitoare la proprietățile imobiliare din nordul Ardealului, în Analele Facultății de Drept din Cluj 1943, p. 262;

T. SZPILA, Laesio enormis a instytucja wyzysku, publicat 23.IV.2014, (data ultimei accesări: 01.09.2019), disponibil la: https://europeanlegalculture.wordpress.com/2014/04/23/laesioenormis-a-instytucja-wyzysku/;

M. S. TEODORU, Laesio enormis, în Gazeta tribunalelor nr. 8-9/1937, p. 4;

R. ZIMMERMANN, The law of obligations. Roman foundations of the civilian tradition, Oxford 1996, pp. 259-270, 373-374. 